\title{
Plant genes involved in harbouring symbiotic rhizobia or pathogenic nematodes
}

\section{Isabelle Damiani ${ }^{1,2,3}$, Fabien Baldacci-Cresp ${ }^{1,2,3}$, Julie Hopkins ${ }^{1,2,3}$, Emilie Andrio ${ }^{1,2,3}$, Sandrine Balzergue ${ }^{4}$, Philippe Lecomte ${ }^{1,2,3}$, Alain Puppo ${ }^{1,2,3}$, Pierre Abad ${ }^{1,2,3}$, Bruno Favery ${ }^{1,2,3 *}$ and Didier Hérouart ${ }^{1,2,3 *}$}

${ }^{1}$ INRA, UMR 1301, Interactions Biotiques et Santé Végétale, 400 route des Chappes, F-06903 Sophia Antipolis, France; ${ }^{2}$ CNRS, UMR 6243, Interactions Biotiques et Santé Végétale,

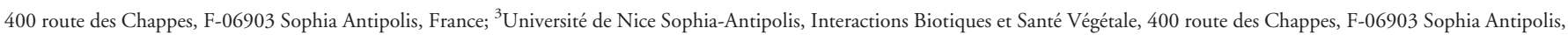
France; ${ }^{4}$ URGV UMR INRA 1165 - CNRS 8114 - UEVE, 2 rue Gaston Crémieux, CP 5708, F-91057 Evry Cedex, France

Authors for correspondence:

Didier Hérouart

Tel: +33 492386464

Email: herouart@unice.fr

Bruno Favery

Tel: +33492386464

Email: favery@sophia.inra.fr

Received: 13 October 2011

Accepted: 18 December 2011

New Phytologist (2012)

doi: $10.1111 / \mathrm{j} .1469-8137.2011 .04046 . x$

Key words: giant cell, laser microdissection, Medicago truncatula, nitrogen-fixing symbiosis, nodule, pathogens, root-knot nematode (RKN), transcriptome.

\section{Summary}

- The establishment and development of plant-microorganism interactions involve impressive transcriptomic reprogramming of target plant genes. The symbiont (Sinorhizobium meliloti) and the root knot-nematode pathogen (Meloidogyne incognita) induce the formation of new root organs, the nodule and the gall, respectively.

- Using laser-assisted microdissection, we specifically monitored, at the cell level, Medicago gene expression in nodule zone II cells, which are preparing to receive rhizobia, and in gall giant and surrounding cells, which play an essential role in nematode feeding and constitute the typical root swollen structure, respectively.

- We revealed an important reprogramming of hormone pathways and C1 metabolism in both interactions, which may play key roles in nodule and gall neoformation, rhizobia endocytosis and nematode feeding. Common functions targeted by rhizobia and nematodes were mainly down-regulated, whereas the specificity of the interaction appeared to involve up-regulated genes.

- Our transcriptomic results provide powerful datasets to unravel the mechanisms involved in the accommodation of rhizobia and root-knot nematodes. Moreover, they raise the question of host specificity and the evolution of plant infection mechanisms by a symbiont and a pathogen.

\section{Introduction}

Plants have to deal with different microorganisms living in the rhizosphere, including devastating pathogens and growth-promoting symbionts. Mutualistic and parasitic biotrophic microorganisms develop stable compatible associations with their hosts, involving a sophisticated exchange of signals. A common feature in biotrophy is the development of specialized interfaces between the microorganisms and the plant cell, over which nutrients are transferred (Harrison, 1999). The development and physiology of these interactions are specific and differ according to the type of microorganism. Nevertheless, the relationships occurring between plants and symbiotic nitrogen-fixing bacteria (such as Sinorhizobium meliloti) or root-knot nematodes (RKNs; Meloidogyne spp.) both lead to the formation of new root structures: nodules and galls, respectively (Fig. 1).

Rhizobia interact strictly with Fabaceae, with the remarkable exception of Parasponia (Lafay et al., 2006). An understanding of nodule formation and functioning is of considerable interest, because it is the zone of atmospheric nitrogen fixation, reducing the need for nitrogen fertilizers for agriculturally important crops

*These authors contributed equally to this work. (e.g. soybean and alfalfa). During this interaction, the cortical and pericycle root cells reinitiate cell divisions, leading to the formation of a nodule primordium. In the case of indeterminate nodules (such as alfalfa and pea), a persistent apical meristem (zone I) develops and gives rise to cells entering the nodule differentiation program, characterized by division arrest, endoreduplication phenomena accompanied by increased cell size (zone II). These cells are infected by bacteria (interzone II-III) which differentiate into a nitrogen-fixing form, called bacteroids. In fixing zone III, bacteroids convert atmospheric nitrogen into ammonia, which is exported to the plant in exchange for carbohydrates (Gibson et al., 2008). This root nodule is indispensable for the nitrogen-fixing symbiont, providing carbon sources and an appropriate environment with a low oxygen pressure required for nitrogenase functioning (Fischer, 1994).

RKNs are obligate sedentary endoparasitic pathogens able to infest thousands of plant species, including monocotyledonous and dicotyledonous herbaceous and woody plants. This wide host range is associated with a worldwide distribution in all temperate and tropical areas, making them extremely successful and damaging parasites (Trudgill \& Blok, 2001). During a compatible interaction, mobile RKN larvae penetrate the root and perform a 

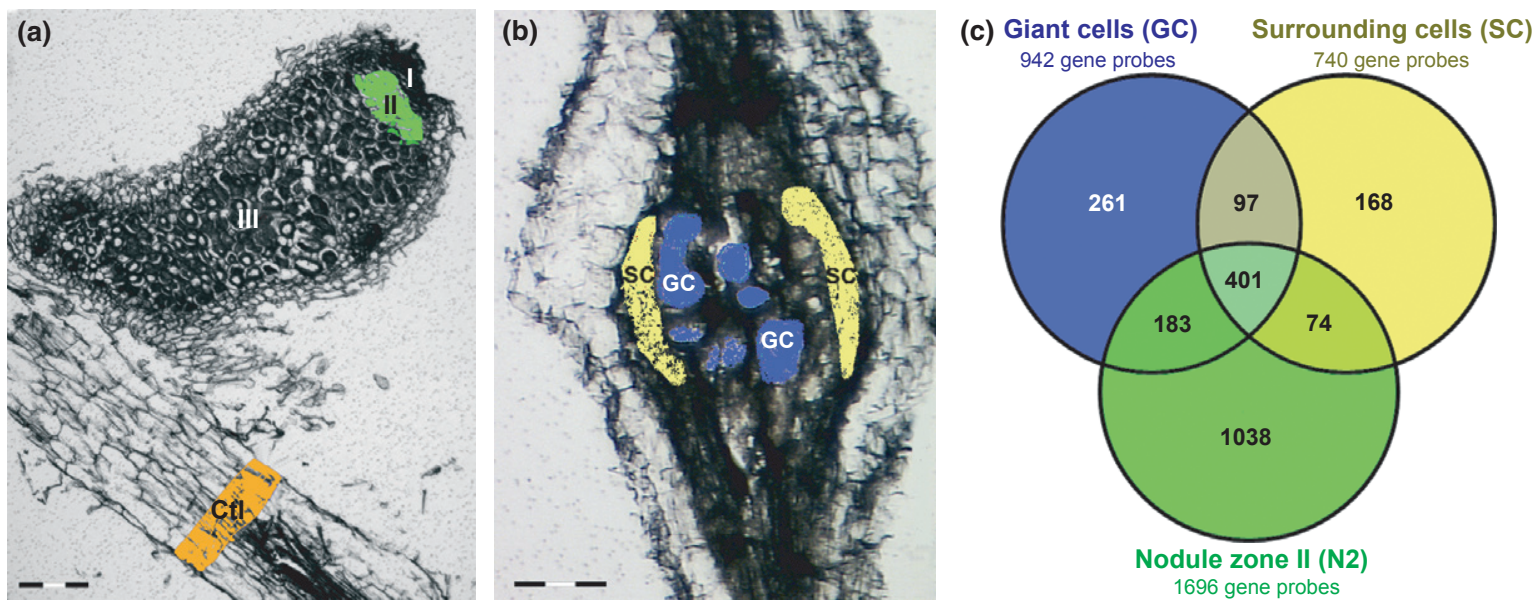

Fig. 1 Transcriptional reprogramming in Medicago truncatula nodule zone II (N2) cells, giant cells (GC) and surrounding cells (SC). (a) Laser microdissected cells of N2 and root control (Ctl). Nodule meristematic zone I and fixation zone III are indicated. (b) Laser microdissected GC and SC induced by Meloidogyne incognita 7 d post-infection. Bars, $200 \mu \mathrm{m}$. (c) Venn diagram showing the differential distribution of 2222 plant gene probes identified as differentially expressed in GC, SC and/or N2 cells. Bars, $200 \mu \mathrm{m}$.

nondestructive migration between cells to reach the root apex and then enter into the vascular cylinder. Once in the stele, RKNs select root parenchyma cells and induce their redifferentiation into multinucleate and hypertrophied feeding cells, termed giant cells (GC). These GC result from repeated nuclear division without complete cytokinesis and isotropic cell growth. In addition, their nuclei may undergo extensive endoreduplication events. The GC cytoplasmic content increases greatly and wall ingrowths develop in contact with the xylem elements. An extensive wall labyrinth forms, increasing the exchange surface area at the associated membrane. These feeding cells function as specialized sinks supplying the nematode with nutrients throughout its life cycle. GC ontogenesis is accompanied by division of the vascular cylinder cells surrounding the GC and the nematode, called surrounding cells (SC). To our knowledge, SC have been given little attention, even though their nematode-induced redifferentiation gives rise to the typical swollen structure of galls, a symptom of nematode infection.

In addition to differences in the invasion process and final structure of these new organs, both are initiated in the differentiated root zone and involve dedifferentiation of specialized cells with a reactivation of the cell cycle followed by redifferentiation (Grunewald et al., 2009). Molecular approaches, including genome-wide expression profiling, have been undertaken to reveal altered gene expression in legume nodules (Benedito et al., 2008; Moreau et al., 2011) and Arabidopsis and tomato galls (Hammes et al., 2005; Jammes et al., 2005; Fuller et al., 2007; Barcala et al., 2010). More recently, material from GCs has been captured using laser microdissection at early stages following infection, showing the molecular distinctiveness of GCs within the gall (Fosu-Nyarko et al., 2009; Barcala et al., 2010). These analyses show that the neoformation of nodules and galls, with their unique morphology and functions, requires extensive changes in gene expression in infected root cells, and highlights that both microorganisms manipulate, for their own purposes, plant host molecular and physiological pathways. Key plant processes, such as hormone balance, defence response, cell wall and cytoskeleton organization and plant metabolism, are affected (Gheysen \& Fenoll, 2002; Benedito et al., 2008; Caillaud et al., 2008; Escobar et al., 2011). Therefore, it is quite conceivable that interactions with rhizobia and nematodes might have evolved certain common core components with an impact on cellular functions (Parniske, 2000; Lipka \& Panstruga, 2005). Indeed, certain nodulin-expressed genes, such as ENOD40 and ENOD11, and two transcription regulators have been shown to be expressed in response to both rhizobia and RKN infections (Koltai et al., 2001; Favery et al., 2002; Boisson-Dernier et al., 2005). A larger scale comparison using macroarrays has revealed that, of 192 noduleexpressed genes, only two, NODULIN26 and CYCLIN D3, were found to be up-regulated on RKN infection (Favery et al., 2002). Moreover, Lotus japonicus nodulation mutants harl and $n f r$ have been found to be hyperinfected and not infected by RKN, respectively (Lohar \& Bird, 2003; Weerasinghe et al., 2005).

To delve into the comparative study of rhizobia and RKN interactions, we focused specifically on cells directly involved in the microorganism's accommodation. Thus, we performed a direct genome-wide comparison using laser-capture microdissected nodule zone II (N2) cells, GC and SC in Medicago truncatula. We chose to compare $\mathrm{N} 2$ cells, which harbour differentiating bacteria at $7 \mathrm{~d}$ post-infection (dpi) GC and SC, which are maturing dedifferentiated plant root cells. These cell types, even though harbouring different functions, can be considered to be at a comparable developmental stage because of their reprogramming fate. This approach allowed us to identify new genes differentially expressed in these tissues and to highlight commonalities and specificities of the processes involved in accommodating rhizobial symbionts and RKN pathogens.

\section{Materials and Methods}

\section{Plant growth and infection}

Seeds from Medicago truncatula Gaertn. cv Jemalong A17 were scarified in $96 \% \mathrm{H}_{2} \mathrm{SO}_{4}(8 \mathrm{~min})$, then in $6 \%$ bleach solution 
( $4 \mathrm{~min}$ ), and rinsed with sterile distilled water. Germination was carried out at $16^{\circ} \mathrm{C}$ for $3 \mathrm{~d}$ on $0.4 \%$ agar plates in the dark. Seedlings were transferred to modified Fahreus medium-containing plates covered with cyg seed germination pouches (Mega International, Moline, IL, USA) and grown in a climatic chamber (16 h photoperiod, $23^{\circ} \mathrm{C}: 16^{\circ} \mathrm{C}$, day: night).

For nematode infection in vitro, 100 surface-sterilized freshly hatched Meloidogyne incognita second-stage juveniles (J2) were added to each 1-wk-old seedling apex. Galls were harvested $1 \mathrm{wk}$ post-infection (wpi). For symbiotic interaction, S. meliloti 2011 lac-Z strain (Ardourel et al., 1994) was grown on LuriaBertani medium, supplemented with $2.5 \mathrm{mM} \mathrm{MgSO}_{4}$, $2.5 \mathrm{mM} \mathrm{CaCl}_{2}$ and $20 \mu \mathrm{M}$ tetracyclin, at $30^{\circ} \mathrm{C}$. One $\mathrm{OD}_{600}$ culture was rinsed twice with sterile water; 1 -wk-old seedlings were inoculated with $200 \mu \mathrm{l}$ of $0.1 \mathrm{OD}_{600}$ bacterial culture. Nodules were harvested at 3 wpi for analysis. Three independent biological replicates comprising 50 plants were grown for each interaction.

\section{Sample preparation for laser capture microdissection}

Tissue fixation, dehydration and paraffin embedding methods were adapted from Kerk et al. (2003). Nodules and galls were collected with a razor blade into ice-cold Farmer's fixative (ethanol : acetic acid, $3: 1 \mathrm{v} / \mathrm{v}$ ), vacuum infiltrated for $15 \mathrm{~min}$ in fresh Farmer's fixative on ice and kept for $2 \mathrm{~d}$ at $4^{\circ} \mathrm{C}$, under shaking conditions, with fixative solution renewed three times a day. Fixed tissues were dehydrated at room temperature in a graded series of ethanol dilutions (3 h each; 70\%, 80\%, 90\%, $100 \%, 100 \%, 100 \%)$ and impregnated progressively in Histo-Clear ${ }^{\circledR}$ (National Diagnostics, Atlanta, GA, USA) (3 h each, 25\%, $50 \%, 75 \%, 100 \%$ three times, $\mathrm{v} / \mathrm{v}$ in ethanol). A few flakes of Paraplast ${ }^{\circledR}$ embedding medium (McCormick Scientific, Richmond, IL, USA) were then added to the final step at room temperature. Once the flakes had dissolved, more flakes were added and vials were transferred to a $60^{\circ} \mathrm{C}$ oven. Three times a day, during $3 \mathrm{~d}$, the embedding medium was replaced by melted Paraplast ${ }^{\circledR}$. Samples were positioned in moulds containing melted Paraplast ${ }^{\circledR}$ and blocks were kept at $4^{\circ} \mathrm{C}$ in dry conditions. Sections of $10-13 \mu \mathrm{m}$ were cut from embedded nodules and galls on a rotary microtome. Ribbons were floated in diethylpyrocarbonate (DEPC)-treated water on polyethylene naphthalate (PEN) membrane slides (Zeiss) and dried overnight. To remove paraffin, slides were immersed in Histo-Clear ${ }^{\circledR}$ for $1 \mathrm{~min}$, followed by ethanol $100 \%$ for $1 \mathrm{~min}$, and dried under the flow-hood.

\section{Laser capture microdissection, RNA extraction and amplification}

The PALM ${ }^{\circledR}$ MicroBeam (Zeiss) was used to microdissect cells from control root $(\mathrm{Ctl}), \mathrm{N} 2, \mathrm{GC}$ and $\mathrm{SC}$ at $\times 10$ magnification. Power settings were adjusted to specifically capture cells of interest without contamination by neighbouring cells. At least 20 galls and nodules were sectioned and an average of 700 and $200 \mathrm{sec}-$ tions, respectively, were dissected for each replicate. Cells were catapulted directly into the adhesive cap of a tube (Zeiss) and kept at $-20^{\circ} \mathrm{C}$ in $5 \mu \mathrm{l}$ of extraction buffer. RNA extraction and DNase treatment were performed following the instructions of the manufacturer with the PicoPure extraction kit (Molecular Devices, Sunnyvale, CA, USA) and RNase-Free DNase Set (Qiagen, Hilden, Germany). RNA quality and quantity were assessed using an RNA 6000 Pico kit on an Agilent 2100 Bioanalyzer according to Agilent Technologies (Waldbroon, Germany).

\section{Microarray experiments, data processing and deposition}

Total RNA was used for amplification following the manufacturer's recommendations with a WT-Ovation ${ }^{\mathrm{TM}}$ Pico RNA Amplification System (NuGEN, Bemmel, The Netherlands). Five micrograms of cDNA were used to generate fragmented and labelled single-stranded cDNA targets with the FL-Ovation ${ }^{\mathrm{TM}}$ cDNA Biotin Module V2 (NuGEN). Microarray hybridization was carried out during $16 \mathrm{~h}$ at $45^{\circ} \mathrm{C}$ at URGV (Evry, France) using the Affymetrix GeneChip ${ }^{\circledR}$ Medicago genome. This array represents over 61200 probe sets: 32167 M. truncatula EST/mRNA-based probe sets; 18733 M. truncatula IMGAG and phase 2/3 BAC prediction-based probe sets; $1896 \mathrm{M}$. sativa EST/mRNA-based probe sets; and $8305 \mathrm{~S}$. meliloti gene prediction-based probe sets. After hybridization, the arrays were washed with stringent $(6 \times$ Saline Sodium Phosphate EDTA (SSPE), $0.01 \%$ Tween-20) and nonstringent (100 mM 2-( $N$-morpholino) ethanesulfonic acid (MES), $0.1 \mathrm{M}\left[\mathrm{Na}^{+}\right], 0.01 \%$ Tween-20) buffer, and stained with a solution including streptavidin Rphycoerythrin conjugate (Invitrogen/Molecular Probes) and anti-streptavidin biotinylated antibody (Vector Laboratories, Burlingame, CA, USA). The washing and staining steps were performed in a GeneChip ${ }^{\circledR}$ Fluidics Station 450 (Affymetrix, Santa Clara, CA, USA). The arrays were finally scanned with the GeneChip $^{\circledR}$ Scanner $30007 \mathrm{G}$ piloted by the GeneChip ${ }^{\circledR}$ Operating Software.

The raw CEL files were imported into $\mathrm{R}$ software for data analysis. All raw data were normalized with the gcrma algorithm (Irizarry et al., 2003), available in the Bioconductor package (Gentleman et al., 2004). To determine differentially expressed genes between two samples, a two-group $t$-test that assumes equal variance between groups was performed. The variance of the gene expression per group is assumed to be homoscedastic; thus, genes displaying extreme variations were excluded from the analysis. The percentages of genes detected as expressed in the Affymetrix GeneChip $^{\circledR}$ in our conditions are given in Supporting Information Table S1. The raw $P$ values were adjusted by the Bonferroni method, which controls the family-wise error rate (Ge et al., 2003). A gene was declared to be differentially expressed if the Bonferroni $P$ value was $<0.05$. Pearson correlation between biological replicates was calculated (Table S2). For Affymetrix GeneChip ${ }^{\circledR}$ annotation, the mapping file 'Mt_AFFY_Mt3.0_0510' was downloaded from the MapMan store (http://mapman.gabipd.org/web/guest/mapmanstore). Ratios were expressed on a $\log _{2}$ scale. Data from 4-, 10-, 14- and 28-dpi nodules were downloaded from the $M$. truncatula gene atlas (MtGEA, http://mtgea.noble.org/v2/) (Benedito et al., 2008). A hierarchical cluster analysis with Pearson correlation and average 
linkage was performed using Cluster and Java tree view software programs.

All raw and normalized data are available through the CATdb database (AFFY_pathogen_Medicago) (Gagnot et al., 2008) and from the Gene Expression Omnibus (GEO) repository at the National Center for Biotechnology Information (NCBI) (Barrett et al., 2007): accession number GSE19872.

\section{Transcriptome validation by quantitative reverse} transcription-polymerase chain reaction (qRT-PCR)

qRT-PCRs were performed using a DNA Engine Opticon 2 Continuous Fluorescence Detection system (MJ Research, ESCO, Singapore) and a qPCR MasterMix Plus for $\mathrm{SYBR}^{\circledR}$ green I (Eurogentec, Angers, France). For each reaction, $5 \mu \mathrm{l}$ of diluted cDNA (50 ng $\mu^{-1}$ ) and $0.3 \mu \mathrm{M}$ primers (Table S3) were used. The PCR conditions were $50^{\circ} \mathrm{C}$ for $5 \mathrm{~min}$ and $95^{\circ} \mathrm{C}$ for $10 \mathrm{~min}$, followed by 40 cycles of $95^{\circ} \mathrm{C}$ for $30 \mathrm{~s}$ and $60^{\circ} \mathrm{C}$ for $1 \mathrm{~min}$. The specificity of the amplification was confirmed by a single peak in a dissociation curve at the end of the PCR. Data were analysed using Opticon Monitor 2 Software (MJ Research) and normalized with the $2^{-\Delta \Delta C T}$ method (Livak \& Schmittgen, 2001). The two most stable housekeeping genes, MTC27 (TC106535) and Mtr23778.1.S1_at probe set (Van de Velde et al., 2006), were validated by the GeNorm VBA applet for MS Excel (Vandesompele et al., 2002) and used as endogenous controls (Vandesompele et al., 2002; Van de Velde et al., 2006). PCRs for each of the three biological replicates were performed in technical triplicate. Transcriptomic profiles were considered to be validated when qRT-PCR replicate ratios had the same tendency.

\section{Promoter:GUS constructs and $\beta$-glucuronidase (GUS) detection in planta}

Genomic DNA fragments of $1.5 \mathrm{~kb}$ upstream of the ATG of NIP1-2 and SPK1 genes were PCR amplified using promoterspecific primers (Table S3) and cloned using Gateway technology (Invitrogen) in the pKGWFS7-GUS vector (Karimi et al., 2002). The resulting plasmids, pNIP1-2:GUS and pSPK1:GUS, were introduced into Agrobacterium rhizogenes Arqua1 (Quandt et al., 1993) and M. truncatula plants (A17) were transformed as described previously (Boisson-Dernier et al., 2001). Transgenic roots were selected through resistance to kanamycin. The composite plants were transferred onto modified Fahraeus media plates containing $1.4 \%$ agar and inoculated 3-4 d after transfer. Galls and nodules were collected at 1 and 3 wpi from RKNs and rhizobia, respectively, and fixed in acetone $90 \%(\mathrm{v} / \mathrm{v})$ for $1 \mathrm{~h}$ at $-20^{\circ} \mathrm{C}$. GUS activity was assayed histochemically at $2-4 \mathrm{~h}$ at $37^{\circ} \mathrm{C}$ as described previously (Favery et al., 2002). Stained nodules were embedded in $4.5 \%(\mathrm{w} / \mathrm{v})$ agarose and sliced at $70 \mu \mathrm{m}$ using a Vibratome (HM560V, Microm, Walldorf, Germany). Stained galls were fixed in $1 \%$ glutaraldehyde, $4 \%$ formaldehyde in $50 \mathrm{mM}$ sodium phosphate buffer, $\mathrm{pH} 7.2$, for $5 \mathrm{~h}$, followed by dehydration and embedding in Technovit 7100 (Heraeus Kulzer, Wehrheim, Germany). Vibroslices and $5-\mu \mathrm{m}$ gall sections were visualized using dark-field optics in an Axioplan2 microscope (Carl Zeiss).

\section{Results}

Transcriptional reprogramming induced by microbes at the site of infection

To study the plant processes targeted by rhizobia and RKNs to aid the interaction, cells from $M$. truncatula root nodules and galls were laser-assisted microdissected (Figs 1, S1). To specifically unravel the molecular changes allowing symbiotic bacteria to colonize and differentiate inside plant cells, we isolated N2 cells from 3-wpi mature nodules, in which rhizobia are endocytosed and become bacteroids (Figs 1a, S1a,b). Three-week-old nodules were chosen because they possess a very well-defined characteristic zone II which can be easily microdissected. In order to minimize cell type variation, root tissues near the nodule emergence zone, corresponding mainly to cortex cells, were dissected from the same sections and used as a control (Ctl) (Figs 1a, S1c,d). To highlight the molecular mechanisms required for RKN establishment, two different cell types constituting the galls, GC and SC, were collected at $7 \mathrm{dpi}$ (Figs 1b, S1e,f). In Medicago, $7 \mathrm{dpi}$ is a relatively early time point considering that $3 \mathrm{wk}$ are required to obtain mature galls, and $7 \mathrm{wk}$ are needed to complete the nematode life cycle. At this stage, GC and SC are still under differentiation, but the dedifferentiation process of plant root cells has already occurred, such as in N2 cells. Genomewide transcriptional changes at the cellular level were monitored for all four microdissected cell types using an Affymetrix Medicago Genome Array®. Of the 61200 probe sets contained in the array, an average of $16.2 \%$ were detected as expressed in our experimental conditions (varying from $11.48 \%$ to $22.32 \%$ for the Ctl and N2 samples, respectively; Table S1). We compared the transcriptomes of N2 cells, GC and SC with the Ctl, and the gene expression profiles of GC to SC directly; 2329 differentially expressed Medicago probe genes, including 99 from M. sativa, were selected by statistical analysis using a cut-off Bonferroniadjusted $P$ value of 0.05 , as described in the Materials and Methods section. Fold changes (gene expression ratios) were expressed on a $\log _{2}$ scale and fell in the range -10.25 to 11.82 (Table S4). A Venn diagram showed that 261 (23\%), 168 (28\%) and 1038 $(61 \%)$ gene probes were specifically deregulated in GC, SC and $\mathrm{N} 2$ cells, respectively, when compared with Ctl cells (Fig. 1c). The number of probe sets (401) responding to both rhizobia and RKNs, for all three types of cell, represented $42 \%, 54 \%$ and $34 \%$ of the deregulated genes in GC, SC and N2 cells, respectively. The 2222 deregulated genes, when compared with Ctl cells, were classified according to their expression profiles in N2 cells, GC and SC. Fifteen major classes explained $98 \%$ of the variations observed (Fig. 2). Only 17\% of these genes were regulated in all three types of cell (profiles $1 \mathrm{a}, \mathrm{b}$ and $\mathrm{c}$ ), whereas $23 \%$ were affected specifically in galls (profiles 2, 4 and 6) and $47 \%$ were differentially expressed specifically in N2 cells. Furthermore, these patterns showed that genes behaved in the same way, except that 107 genes were up-regulated in N2 cells and down-regulated in GC and SC. The majority of the deregulated genes in GC and SC were down-regulated: $68 \%$ and $70 \%$, respectively. Nevertheless, GC- and SC-specific genes were 
mainly up-regulated. In N2 cells, the proportion of up- and down-regulated genes was more balanced, with 59\% being up-regulated.

To validate our data, we performed a qRT-PCR analysis on microdissected N2, GC, SC and Ctl samples for eight genes, chosen as representative of the whole range of expression levels observed on the arrays (Fig. 3a). These genes belong to various functional categories, such as biotic and abiotic stress response (EDS1 and $M L P$, encoding an enhanced disease susceptibility and a major latex protein, respectively), transport ( $A M T$, encoding an ammonium transporter), protein synthesis ( $R P-L 2$, encoding a ribosomal protein), detoxification (GSTU and FD3, encoding a glutathione- $S$ transferase and a nonphotosynthetic ferredoxin, respectively) and nodulins (NCR001 and NCR333, encoding two nodule-specific cystein rich peptides). The qRTPCR study verified $81 \%$ of the DNA array hybridization results. Moreover, the expression patterns of known marker genes were checked for each tissue (Gamas et al., 1998; Maunoury et al., 2010; Moreau et al., 2011) (Table S5). The zone II-expressed genes MtRR4, MtENOD11, MtN1 and SPP were effectively up-regulated in N2 cells, whereas $M t N 13$, specifically expressed in zone I, was not differentially expressed. In addition, $70 \%$ of the deregulated genes in Arabidopsis microdissected GC from young galls (Barcala et al., 2010), and having a homologue in the Medicago Affymetrix gene chip, shared the same expression profile with our samples (Table S6). To further confirm the identity of microdissected cells, we produced composite transgenic Medicago reporter lines expressing promoter:GUS constructs for genes encoding an aquaporin (NIP1-2) and a protein kinase-like (SPK1) (Fig. 3). GUS expression was detected in N2 cells and also in nodule zone I (Fig. 3a,b), but not in GC or SC (Fig. 3c,d). Thus, these three different strategies validated our microarray results and confirm the purity of laser capture microdissected samples.

\section{Characteristics of gene expression in nodule infection zone II}

We identified 708 down- and 988 up-regulated genes in N2 cells. The expression profiles of these 1696 genes were investigated in whole-nodule transcriptome studies at 4 (bumps corresponding to nodule emergence), 10 (mature nodules), 14 and $28 \mathrm{dpi}$ (nitrogen-fixing nodules) from the $M$. truncatula gene atlas (MtGEA) (Benedito et al., 2008) (Table S7). A hierarchical cluster analysis with Pearson correlation and average linkage showed that the transcriptome of $\mathrm{N} 2$ cells represents an original set of data more closely related to 10-, 14- and 28-dpi nodules than to 4-dpi nodule bumps (Fig. 4a). Interestingly, we identified a new pool of genes differentially expressed in zone II and not yet detected in whole nodules, including 257 down- and 288 up-regulated genes. A functional classification of these genes, combined with a statistical analysis using the MapMan Wilcoxon rank sum test (Thimm et al., 2004), showed that the main processes impaired specifically in zone II were glycolysis, mitochondrial electron transport/ATP synthesis, secondary metabolism and protein-related functions (Table S8). Nevertheless, among them, 233 were of unknown function. A detailed analysis of common features between N2 cells and 10-, 14- and 28-dpi whole nodules showed that 172 and 501 genes were down- and up-regulated, respectively, in all conditions tested. These deregulated genes belong to metabolic pathways already described by Benedito et al. (2008) as affected during nodule development, such as the induction of glycolysis, carbon fixation, nitrogen metabolism and repression of secondary metabolism. Only six genes behaved in an opposite way in zone II relative to all developmental stages of the whole nodules considered (Table S6). Special attention was paid to nodulin genes and, in particular, to NCR genes, which are nodule specific and involved in nodule formation (Mergaert et al., 2003) (Table S9). One hundred and twenty-two of the 328 characterized NCRs (Mergaert et al., 2003) were up-regulated in N2 cells. All the probe sets related to nodulin and NCR, deregulated in zone II, have been shown to be up-regulated in whole-nodule transcriptomes. We also detected N2 up-regulation of the DNF1 gene (Mtr.43876.1.S1_at), which encodes a member of the nodule-specific signal peptidase complex (SPC) required for NCR targeting and essential for bacteroid differentiation and symbiosome development (Van de Velde et al., 2010).

Classification of the 1696 deregulated genes in N2 cells using MapMan showed the metabolic processes that were altered in zone II (Fig. 4b). Most categories have a higher number of upregulated genes, except for the photosystem, stress, transport, cell
Fig. 2 Major expression profiles identified in Medicago truncatula nodule zone II (N2) cells, giant cells (GC) and surrounding cells (SC). The 15 major expression profiles describe $98 \%$ of the 2222 differentially regulated genes. Down-regulated genes are indicated in green, up-regulated genes in red and no differentially expressed genes in grey.

\begin{tabular}{|c|c|c|c|c|c|}
\hline Profiles & GC & SC & N2 & \multicolumn{2}{|c|}{ Gene probe number } \\
\hline $1 a$ & & & & 250 & \\
\hline $1 \mathrm{~b}$ & & & & 107 & GC \& SC \& N2 \\
\hline $1 \mathrm{c}$ & & & & 33 & \\
\hline $2 a$ & & & & 57 & \\
\hline $2 b$ & & & & 38 & GC \& SC \\
\hline $3 a$ & & & & 27 & \\
\hline $3 b$ & & & & 28 & $\mathrm{SC} \& \mathrm{~N} 2$ \\
\hline $4 a$ & & & & 39 & \\
\hline $4 b$ & & & & 129 & SC specific \\
\hline $5 a$ & & & & 145 & \\
\hline $5 b$ & & & & 27 & GC \& N2 \\
\hline $6 a$ & & & & 82 & GC specific \\
\hline $6 b$ & & & & 179 & \\
\hline $7 a$ & & & & 262 & N2 snecific \\
\hline $7 \mathrm{~b}$ & & & & 776 & NO specillic \\
\hline
\end{tabular}


(a)

\begin{tabular}{|c|c|c|c|c|c|c|c|c|c|c|c|}
\hline (a) & & & $\mathrm{N} 2 \mathrm{v}$ & $\mathrm{sCtl}$ & GC & $\mathrm{sCtl}$ & SC & s Ctl & GC v & vs SC & Valid \\
\hline Affymetrix ID & Gene name & Annotation & Affy & $\mathrm{qPCR}$ & Affy & qPCR & Affy & $\mathrm{qPCR}$ & Affy & qPCR & \\
\hline Mtr.12287.1.S1_at & GSTU & Glutathione S-transferase & -1.78 & -0.56 & & & & & & & 0 \\
\hline Mtr.10380.1.S1_at & NCR001 & Nodule-specific cysteine-rich & 2.93 & 3.12 & & & & & & & 1 \\
\hline Mtr.3244.1.S1_at & NCR333 & Nodule-specific cysteine-rich & 1.74 & 2.86 & & & & & & & 1 \\
\hline Mtr.10572.1.S1_at & MLP & Major latex protein & -6.92 & -6.17 & -1.55 & 0.74 & & & -1.63 & -4.82 & 3 \\
\hline Mtr.10531.1.S1_at & EDS1 & Enhanced disease susceptibility 1 & -4.62 & -2.91 & -2.05 & -4.80 & 1.17 & 0.66 & -2.42 & -5.65 & 4 \\
\hline Mtr.16296.1.S1_at & RP-L2 & Ribosomal protein L2 & 2.06 & 2.30 & 1.69 & 3.00 & 2.01 & 2.05 & -0.32 & 0.78 & 4 \\
\hline Mtr.10556.1.S1_at & AMT & Ammonium transporter & -2.46 & -2.60 & -2.06 & 0.34 & 1.32 & 0.21 & -2.80 & -3.96 & 3 \\
\hline Mtr.40420.1.S1_at & FD3 & Ferredoxin & -1.69 & -0.68 & 0.21 & 2.10 & 2.70 & 3.50 & -2.50 & -2.34 & 2 \\
\hline (b) & & (c) & d) & & & & (e) & & & & \\
\hline
\end{tabular}

Fig. 3 Validation of microarray data. (a) Quantitative reverse transcription-polymerase chain reaction (qRT-PCR) experiments. Validated comparisons between microarray and qRT-PCR results are shown in the same colour. Down-regulated genes are indicated in green, up-regulated genes in red and no differentially expressed genes between the two conditions in grey. N2, nodule meristematic zone II; Ctl, root control cells; GC, giant cells; SC, surrounding cells. (b-e) Composite transgenic Medicago truncatula reporter lines expressing promoter:GUS constructs. Dark-field micrographs of root sections after $\beta$ glucuronidase (GUS) staining of 3-wk post-infection nodules $(b, c)$ and 7-d post-infection galls $(d, e)$. (b) and (d) correspond to the promoter of aquaporin NIP1-2 (Mtr.2246.1.S1_at), and (c) and (e) to the promoter of the protein kinase-like SPK1 (Mtr.16214.1.S1_at). Nodule meristematic zones I, II and III are indicated. * , giant cells; $\mathrm{N}$, nematode. Bars, $200 \mu \mathrm{m}$.

(a)

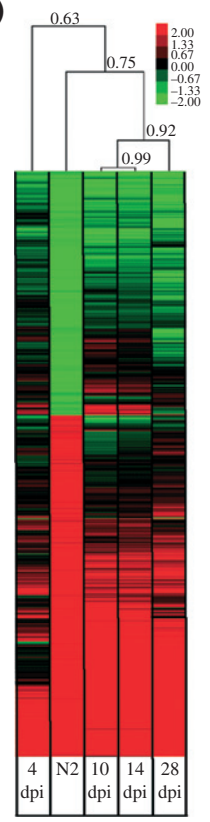

(b)

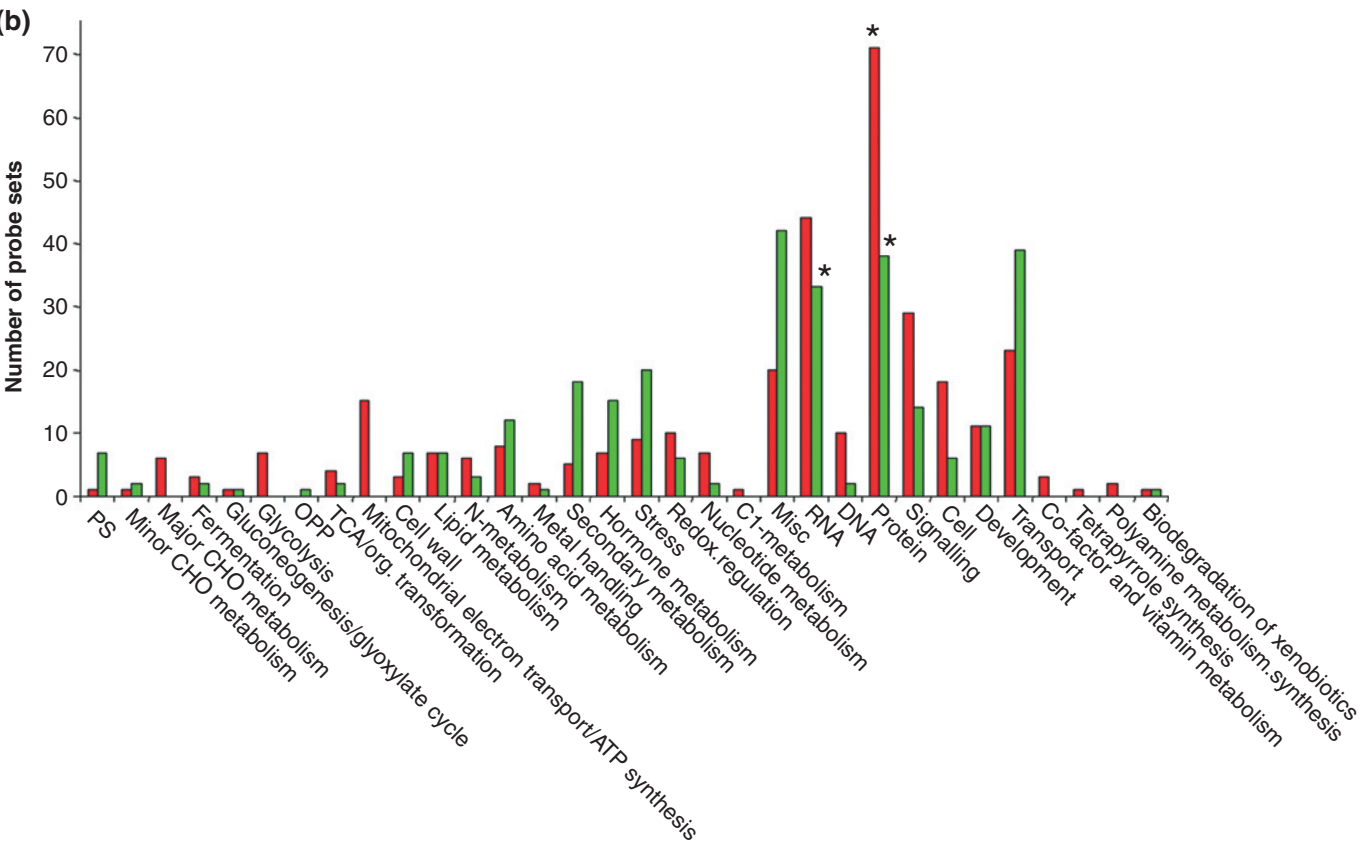

Fig. 4 Gene clusters and main functional classes affected in nodule zone II (N2) cells. (a) Hierarchical cluster analysis of genes differentially expressed in N2 cells and in Medicago truncatula whole nodules at different time points. Data from nodules at 4, 10, 14 and $28 \mathrm{~d}$ post-infection (dpi) were obtained from the $M$. truncatula gene atlas (MtGEA) and compared with root control or denodulated root, respectively. The hierarchical analysis was carried out with Pearson correlation and average linkage. (b) Main functional classes affected in N2 cells. The $y$-axis represents the number of probe sets deregulated in $\mathrm{N} 2$ cells relative to control root cells. Red and green correspond to up- and down-regulated genes, respectively. ${ }^{*}, P \leq 0.05$ as calculated by MapMan Wilcoxon rank sum test according to the MapMan gene ontology.

wall and amino acid, secondary and hormone metabolisms. In addition to the expected decrease in stress/defence-associated responses, pathways statistically affected support the needs for metabolic changes and preparation to an anaerobic environment for good functioning of the nodule. Thus, we observed the up-regulation of the mitochondrial/electron transport and ATP synthesis machineries, and RNA and protein-related processes. Interestingly, 12 of the 15 up-regulated genes annotated as 'Mitochondrial electron transport/ATP synthesis' were not detected as deregulated in whole nodules. MapMan 
representation of the mitochondrial electron chain confirmed the original pattern of gene expression in N2 cells, which could reflect mitochondrial adaptation to the decrease in oxygen partial pressure (Fig. S2).

\section{Characteristics of gene expression in $\mathrm{GC}$ and $\mathrm{SC}$ of the gall}

Transcript profiling of isolated GC and SC induced by RKNs at 7 dpi revealed 942 and 740 deregulated genes in GC and SC, respectively, relative to $\mathrm{Ctl}$ cells. Four hundred and ninety-four probe sets were commonly affected in GC and SC. A direct comparison between GC and SC transcriptomes showed 190 downand 95 up-regulated genes, including 129 deregulated genes not differentially expressed when either GC or SC were compared with the Ctl (Table S4). Among the 651 genes down-regulated in GC, 63\% were also down-regulated in SC, whereas 36\% were not differentially expressed in SC. Only $28 \%$ of the 287 upregulated genes in GC were also up-regulated in SC (Fig. 5a). Previous genome-wide microarray studies on the plant-RKN interaction have concerned mainly A. thaliana (Jammes et al., 2005; Barcala et al., 2010), making the comparison with our microarray data difficult. According to the Medicago Affymetrix gene chip annotation, 471 putative Arabidopsis orthologous genes were found among the 942 GC deregulated genes in Medicago galls, and only 58 were differentially expressed in GC at 3 dpi (Barcala et al., 2010) (Table S6).

Classification of the deregulated genes in GC and SC using MapMan showed the main functional classes that were affected. In contrast with N2 analysis, most categories had a higher number of down-regulated genes in GC and SC (Fig. 5b, arrows). Pathways statistically affected were different between GC and
SC. GC showed an up-regulation of protein, DNA and C1 metabolism and also a down-regulation of secondary metabolism. If we consider the subclasses of the 'protein' functional category, protein synthesis was highly increased in GC, whereas other classes, such as protein modifications or degradation, were mainly down-regulated (Fig. S3). Such an impact on protein synthesis was not detected in SC, where a statistical up-regulation of 'cell', 'signalling' and 'cell wall'-related pathways was shown.

\section{Common features and specificities}

The establishment of these symbiotic and pathogenic interactions led to the regulation of mainly specific and some common genes (Fig. 1c). Of the 401 probe sets deregulated in all three types of cell already mentioned (Fig. 1c), 33 and 249 were up- and down-regulated, respectively, and 118 behaved in opposite ways, between N2 cells and GC or SC. N2 cells shared more regulated genes with GC (183) than with SC (74) (Figs 1c, 2). According to a MapMan Wilcoxon rank sum test, the 'protein synthesis' functional class was statistically affected in response to both nematode and rhizobium infections.

Legume-specific genes, with no sequence homology to publicly available sequences of nonleguminous plants (Graham et al., 2004), represent 5842 probe sets on the Medicago gene chip (Benedito et al., 2008). Among them, 457 were deregulated in at least one of the cell types considered in this study, including 210 in galls (Table S10). The functions of these gene products are quasi-exclusively unknown.

Particular attention was paid to transcription factors (TFs), because of their role in determining the specific cell fate. Among the TF coding genes depicted by Benedito et al. (2008) and (a)

Giant cells (GC) Surrounding cells (SC)
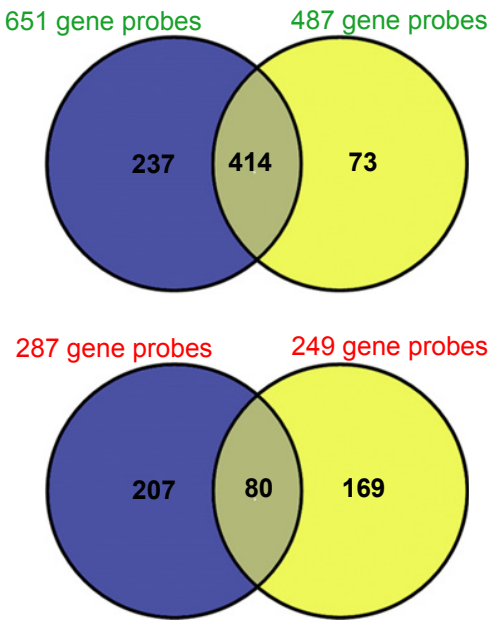

(b)

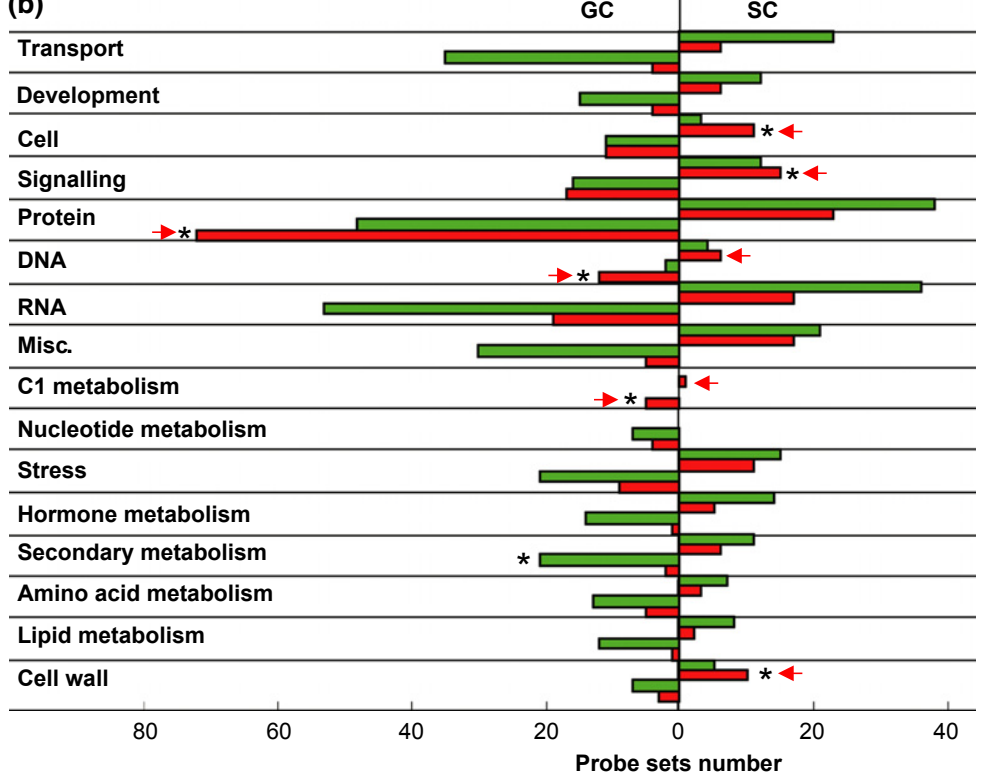

Fig. 5 Transcriptome comparison of giant cells (GC) and their surrounding cells (SC) in Medicago truncatula galls induced by Meloidogyne incognita. (a) Venn diagrams showing the distribution of down-regulated (green) and up-regulated (red) genes in GC and SC. (b) Main functional classes affected in GC and SC. The $y$-axis represents the number of probe sets deregulated. Red and green correspond to up- and down-regulated genes, respectively, and red arrows to functional classes with more up- than down-regulated genes. ${ }^{*}, P \leq 0.05$ as calculated by MapMan Wilcoxon rank sum test according to the MapMan gene ontology. 
Moreau et al. (2011), 101 were deregulated in at least one of our comparisons, including 87, 45 and 38 in N2 cells, GC and SC, respectively (Table S11). Interestingly, TF coding genes were mainly down-regulated in all three types of cell, with only two up-regulated in GC. N2 cells, GC and SC share a large proportion of down-regulated TF genes. For example, $79 \%$ and $67 \%$ of the GC down-regulated probe sets were also repressed in SC and $\mathrm{N} 2$ cells, respectively. Meanwhile, there were no commonly regulated TFs between all three GC, SC and N2 cells. Interestingly the orthologue of WOX4 (Mtr.23994.1.S1_at), encoding a WUSCHEL-related homeobox TF, was shown to be specifically up-regulated in SC.

Finally, we focused our comparisons on hormone pathways and responses (Table S12). Although only the down-regulation of genes related to auxin was detected in N2 cells (encoding two auxin-responsive proteins and one related to auxin signalling), one gene was induced in galls (GC and SC). This gene encodes an influx carrier, named AUX1-like or LAX (Arabidopsis corresponding orthologue At2g38120). The N2 transcriptome revealed three genes involved in cytokinin signalling, which respond to rhizobia, as already shown in whole nodules (Benedito et al., 2008), but which were not affected following nematode infection. One gene was down-regulated in N2 cells, whereas two were up-regulated, including the zone II MtRR4 marker mentioned above. The probe set encoding the last enzyme of the ethylene biosynthesis pathway, 1-aminocyclopropane-1-carboxylate oxidase (ACC oxidase, Mtr.43104.1.S1_at), was down-regulated in N2 cells, GC and SC. This down-regulation was accompanied by a decrease in expression of an ethylene-response factor encoding gene (Mtr.38122.1.S1_at) in the three types of cell. This tendency for a decrease in the ethylene response was confirmed in $\mathrm{N} 2$ cells and GC through the down-regulation of seven and four other probe sets, respectively (including three in common). In addition to this reduction, in $\mathrm{N} 2$ cells, five genes related to the ethylene response were up-regulated. Three genes related to the gibberellin (GA) response were also increased: one in N2 cells (Mtr.9046.1.S1_at) and two in SC (Mtr.43746.1.S1_at and Mtr.48768.1.S1_at), but not in GC. We also observed the down-regulation of various genes encoding repressors of the GA response (DELLA proteins), proteins involved in GA catabolic processes and a GA receptor. This decrease was verified in all three types of cell, but it had an impact on distinct genes in N2 cells, GC and SC, which could reflect the different developmental processes involved. Genes involved in the synthesis of jasmonic acid (JA) and its derivatives were down-regulated in N2 cells, GC and SC. Lipoxygenases (LOXs) encoding probe sets were classified into the JA-related category, even though it was unclear which members of this multigene family were effectively involved in this pathway.

\section{Discussion}

Features of pathogenic and symbiotic relationships have led to the proposed concept of 'variations on a common theme' (Baron $\&$ Zambryski, 1995). Indeed, although there are also a number of unique attributes to each category of interaction, symbiosis and pathogenesis clearly appear to be two sides of the same coin (Ausubel \& Bisseling, 1999), and microbes can transition between the trophic states of pathogenesis and symbiosis (Newton et al., 2010). To address the question of the conservation of target plant genes and the functions deregulated following interaction with a symbiont and a pathogen, a large-scale comparison was performed using microdissected tissues in M. truncatula. This leguminous plant has proven to be a model of choice because it is able to develop a nitrogen-fixing symbiotic interaction with rhizobia and is a host for RKNs. Taking into account the complexity of the new root structures induced by $S$. meliloti and $M$. incognita, that is, nodules and galls, respectively, our original approach at the cellular level allowed us to specifically unravel the genome-wide transcriptome changes involved in the establishment of the microorganisms. Our analysis revealed the hitherto unexplored gene expression patterns of N2, where plant cells are preparing to receive rhizobia. In parallel, the divergent gene expression profiles observed between GC and their SC provided novel data on the molecular events occurring in these highly specialized cells, reflecting their specific functions during the interaction. Laser capture microdissection allowed us to highlight the genes expressed in GC, SC and N2 cells, even those which were weakly expressed and thus could not be detected when the transcriptome concerned the entire organ. This statement is in accordance with the dilution of GC transcripts observed in Arabidopsis galls (Barcala et al., 2010). In addition to a common core, we report the specificity of both interactions, reflecting the main purpose of the microorganism infection. Thus, 1038, 261 and 168 genes were specifically deregulated in N2 cells, GC and SC, respectively. Furthermore, this genomewide analysis showed a significant number of common target genes of rhizobium and RKN infections; 250 and 33 genes were down- and up-regulated, respectively, in the three types of cell, compared with the c. 10 genes already reported (Favery et al., 2011). Taken together, our data strongly suggest that downregulation mechanisms are more conserved than those involved in the induction of genes between a symbiotic and a pathogenic interaction. Thus, the specificities of each interaction seem to be related more to the up-regulation of specific pathways or gene family members.

This was first illustrated by the massive down-regulation of genes involved in plant stress and defence - especially the phenylpropanoid/flavonoid pathways - in good agreement with previous reports on entire nodules (Maunoury et al., 2010; Moreau et al., 2011), Arabidopsis galls (Jammes et al., 2005) or dissected GC at 3 dpi (Barcala et al., 2010). We further showed that there was a greater decrease in secondary metabolism and stress-related genes in GC than in SC. This localized repression of plant defence genes in cells in direct contact with the microorganisms is in accordance with an effective suppression of defences by secreted effectors of nematode or symbiotic bacteria. The JA pathway, which has been associated with pathogen resistance, also appeared to be down-regulated in N2 cells, GC and SC (Table S12). Furthermore, the down-regulation of $L O X$ genes in N2 cells, GC and SC was in accordance with their putative role in plant defence, knowing that a reduction in 
LOX activity increases plant susceptibility (Ibrahim et al., 2011). Ethylene also plays a role in the plant biotic stress response, growth and development. Transcripts encoding proteins involved in ethylene synthesis, ACC synthase and ACC oxidase, have been shown to be decreased in soybean roots infected by a cyst nematode relative to a noninfected root (Puthoff et al., 2007). This decrease in ethylene metabolism has also been described during the Medicago-rhizobium interaction (Oldroyd et al., 2001). In agreement with these data, we found a decrease in transcripts encoding proteins involved in ethylene synthesis in gall GC and SC, as well as in N2 cells. We also observed the down-regulation of an ethylene-responsive $\mathrm{TF}$ RAP2-4 in N2 cells and GC, which binds to pathogenesisrelated promoter elements and may be involved in the regulation of gene expression by stress factors and by components of stress signal transduction pathways (Lin et al., 2008).

Interestingly, our statement with regard to the down- vs up-regulated gene conservation was further confirmed by the case of TFs, which were mainly down-regulated in all three types of cell, with none being up-regulated in common (Table S11). An interesting example of an up-regulated TF gene specific to one interaction is the orthologue of WOX4, encoding a WUSCHEL-related homeobox TF. It was specifically increased in SC. We hypothesize that WOX4 would regulate proliferation in SC, as shown in vascular stem cells. By contrast, its repression in differentiating GC highlights the loss of the vascular cell identity in this novel cell type induced by RKNs. Other striking examples are genes encoding remorins, which are part of a multigene family potentially involved in plant defence (Jarsch \& Ott, 2010). Two members of this family (Mtr.37637.1.S1_at and Mtr.43807.1.S1_at) were shown to be down-regulated in the three types of cell in our microarrays, whereas one remorin encoding gene, MtSYMREM1, was specifically up-regulated in N2 cells. MtSYMREM1 has been shown to favour bacterial release from infection threads into plant cells (Lefebvre et al., 2010). This gene was not deregulated in gall GC and SC, indicating that it does not play a role in allowing RKNs to develop a compatible pathogenic interaction with Medicago. Taken together, these data confirm that MtSYMREM1 function is specifically involved in rhizobium infection and nodule development. Interestingly, two probe sets of MtIPD3 were up-regulated in N2 cells only, which is in agreement with recent results indicating that MtIPD3 is required for the correct expression of nodule-specific remorin (Limpens et al., 2011).

We also observed a large modulation of plant hormone balance, which is known to play a role in the integration of internal and external stimuli to regulate various aspects of plant growth and development (Table S12). Auxin is essential for plant organogenesis through the regulation of embryogenesis, meristem formation, cell division and elongation, and should play a key role in nodule and gall initiation and/or development (Grunewald et al., 2009). In indeterminate nodules, following a local and transient auxin transport inhibition, an increase in auxin response was reported in early dividing cells in the pericycle and inner cortex, leading to nodule primordium (Mathesius et al., 1998; van Noorden et al., 2007). During later stages of nodule development and differentiation, the expression of auxin response genes was decreased. As supported by these experiments, we found the down-regulation of auxin signalling and response genes in N2 (Table S12), where division had already stopped. The downregulation of $J A R 1$, an auxin-induced gene involved in the catalysis of the formation of jasmonyl-isoleucine conjugates, in all three types of cell is consistent with the decrease in the auxin pool. Although only down-regulated auxin-related genes were detected in N2 cells, one gene was induced in both GC and SC, encoding an AUX1-like auxin influx carrier, as reported previously in response to RKNs and cyst nematodes (Mazarei et al., 2003; Hammes et al., 2005; Jammes et al., 2005; Barcala et al., 2010). In addition, we observed an increase in the expression of the A-type response regulator primary response cytokinin gene (MtRR4) only in N2 cells, which further supports a role for this phytohormone in nodule cell differentiation (Moreau et al., 2011; Plet et al., 2011). Furthermore, we revealed that another member of the two-component system, the response regulator ATRR3, involved in transduction of the cytokinin signal, may play a similar role in $\mathrm{N} 2$ cells. Thus, both genes seem to have the same regulation in nodulation, in addition to their described opposing cytokinin response in Arabidopsis shoot and callus (Osakabe et al., 2002). By contrast, no impact on the cytokinin pathway could be detected in GC or SC, which may be consistent with an initial transient need for cytokinin during GC initiation (Goverse \& Bird, 2011). Few ethylene-related genes were upregulated in $\mathrm{N} 2$ cells, including $M B F 1$, a transcriptional coactivator gene involved in the regulation of the cross-talk between ethylene, abscisic acid (ABA) and stress signalling pathways (Arce et al., 2010).

The transcriptional reprogramming revealed in our microarrays also affects the functioning of organelles, as shown by enhanced expression of pentatricopeptide repeat $P P R$ genes in zone II, which are known to play a role in post-transcriptional processes in organelles (Saha et al., 2007). Interestingly, other probe sets encoding PPRs are up-regulated in metabolically active GC which contain a dense cytoplasm with an increased number of organelles (Jones, 1981). Thus, such an impact on protein synthesis, as revealed in our microarray experiment in GC but not in $\mathrm{SC}$, seems obvious. The up-regulation of specific genes belonging to amino acid metabolism is consistent with the role of GC in nematode nutrition. 'Protein synthesis' in N2 cells was less affected than in GC, but the subcategory 'protein targeting' was strongly increased, probably to support and allow rhizobium endocytosis and/or differentiation.

Furthermore, an impact of rhizobia or RKN infection on Medicago primary metabolism was also observed. As an example, the up-regulation of genes encoding a phosphoenol pyruvate carboxylase (PEPc) and a plant neutral invertase, in N2 cells, could be necessary to support the need for carbon skeletons as a result of the endocytosis of rhizobia, which are becoming energetically dependent on plants. This hypothesis is reinforced by the absence of the deregulation of these genes in whole nodules (Table S7). By contrast, this plant neutral invertase and a sucrose synthase encoding transcript were down-regulated in GC, which is 
consistent with the sucrose increase found in Medicago galls (Baldacci-Cresp et al., 2011) and the presence of a putative invertase encoding gene in the $M$. incognita genome (Abad et al., 2008). Thus, the accumulation of sucrose following nematode infection may serve as a carbon source, complementary to starch, for RKNs. Indeed, in contrast with the vast majority of animals, Meloidogyne spp. possess the enzymatic machinery to metabolize sucrose. In addition, sucrose may support the modification of the cell osmotic status with GC differentiation. However, the nematode feeding function of GC is also supported by a significant increase in $\mathrm{C} 1$ metabolism. These data help to complete our limited knowledge on the metabolic processes responding to the nematode demand in plant cells (Grundler \& Hofmann, 2011). For example, a gene encoding a dihydroneopterin aldolase, an enzyme of the folate biosynthesis pathway (Goyer et al., 2004), was up-regulated in GC (Table S4). Previous reports have indicated that helminths are not able to synthesize de novo folate (Weinstein \& Jaffe, 1987), similar to higher animals, which lack a complete folate synthesis pathway, and therefore need a dietary supply. In the nematode Caenorhabditis elegans, the FOLT-1 transporter is involved in the uptake of exogenous folate, and its mutation causes nematode sterility (Austin et al., 2010), confirming the need for the nematode to use an external source of folate. Such an impact on the folate biosynthesis pathway was not detected in N2, which is not supposed to have a feeding function for the symbiont.

Legumes, because of their ability to form a symbiotic interaction with soil bacteria, are set apart from other plant families. They possess specific features, such as genes termed legumespecific', which show no sequence homology with any of the publicly available sequences. Their regulation following RKN infection (Table S10) raises the question of host specificity and evolution, because these nematodes are able to develop a compatible interaction with a wide range of hosts, but, at the same time, can modulate legume-specific genes. We can hypothesize that this gene deregulation is either an indirect consequence of the interaction, or RKNs are able to specifically recognize their host and adapt to their specificity. Taken together, all of these data clearly show that the infection zone acts as a transition zone between root-type and nodule-type tissues. Moreover, they reveal new pathways necessary for the development of the plant-nematode interaction and provide new information on the specific role of GC and SC. Thus, new targets for pest control, whilst favouring nitrogen enrichment, could be defined on the basis of these new datasets.

\section{Acknowledgements}

This work was supported by a postdoctoral fellowship (I.D.) granted by the Centre National de la Recherche Scientifique (CNRS) and by an innovative grant from the INRA Division 'Plant Health and Environment'. We thank Drs L. Chantalat and P. Reiniche (GALDERMA Research \& Development), and C. Rothan, N. Frangne and J. Petit (INRA - Bordeaux University, France), for fruitful discussions and access to the PALM microscope.

\section{References}

Abad P, Gouzy J, Aury JM, Castagnone-Sereno P, Danchin EG, Deleury E, Perfus-Barbeoch L, Anthouard V, Artiguenave F, Blok VC et al. 2008. Genome sequence of the metazoan plant-parasitic nematode Meloidogyne incognita. Nature Biotechnology 26: 909-915.

Arce DP, Godoy AV, Tsuda K, Yamazaki K-I, Valle EM, Iglesias MJ, Di Mauro MF, Casalongué CA. 2010. The analysis of an Arabidopsis triple knock-down mutant reveals functions for MBF1 genes under oxidative stress conditions. Journal of Plant Physiology 167: 194-200.

Ardourel M, Demont N, Debelle F, Maillet F, de Billy F, Prome JC, Denarie J, Truchet G. 1994. Rhizobium meliloti lipooligosaccharide nodulation factors: different structural requirements for bacterial entry into target root hair cells and induction of plant symbiotic developmental responses. Plant Cell 6: 1357-1374.

Austin MU, Liau WS, Balamurugan K, Ashokkumar B, Said HM, LaMunyon CW. 2010. Knockout of the folate transporter folt- 1 causes germline and somatic defects in C. elegans. BMC Developmental Biology 10: 46.

Ausubel F, Bisseling T. 1999. Biotic interactions pathogenesis and symbiosis: two sides of the same coin that should be united by a common web-accessible database: editorial overview. Current Opinion in Plant Biology 2: 265-267.

Baldacci-Cresp F, Chang C, Maucourt M, Deborde C, Hopkins J, Lecomte P, Bernillon S, Brouquisse R, Moing A, Abad P. 2012. (Homo)glutathione deficiency impairs root-knot nematode development in Medicago truncatula. PLoS Pathogens 8: e1002471.

Barcala M, Garcia A, Cabrera J, Casson S, Lindsey K, Favery B, Garcia-Casado G, Solano R, Fenoll C, Escobar C. 2010. Early transcriptomic events in microdissected Arabidopsis nematode-induced giant cells. The Plant Journal 61: 698-712.

Baron C, Zambryski PC. 1995. The plant response in pathogenesis, symbiosis, and wounding: variations on a common theme? Annual Review of Genetics 29: $107-129$.

Barrett T, Troup DB, Wilhite SE, Ledoux P, Rudnev D, Evangelista C, Kim IF, Soboleva A, Tomashevsky M, Edgar R. 2007. NCBI GEO: mining tens of millions of expression profiles - database and tools update. Nucleic Acids Research 35: D760-D765.

Benedito VA, Torres-Jerez I, Murray JD, Andriankaja A, Allen S, Kakar K, Wandrey M, Verdier J, Zuber H, Ott T et al. 2008. A gene expression atlas of the model legume Medicago truncatula. The Plant Journal 55: 504-513.

Boisson-Dernier A, Andriankaja A, Chabaud M, Niebel A, Journet EP, Barker DG, de Carvalho-Niebel F. 2005. MtENOD11 gene activation during rhizobial infection and mycorrhizal arbuscule development requires a common AT-rich-containing regulatory sequence. Molecular Plant-Microbe Interactions 18: 1269-1276.

Boisson-Dernier A, Chabaud M, Garcia F, Bécard G, Rosenberg C, Barker DG. 2001. Agrobacterium rhizogenes-transformed roots of Medicago truncatula for the study of nitrogen-fixing and endomycorrhizal symbiotic associations. Molecular Plant-Microbe Interactions 14: 695-700.

Caillaud MC, Dubreuil G, Quentin M, Perfus-Barbeoch L, Lecomte P, de Almeida Engler J, Abad P, Rosso MN, Favery B. 2008. Root-knot nematodes manipulate plant cell functions during a compatible interaction. Journal of Plant Physiology 165: 104-113.

Escobar C, Brown S, Mitchum M. 2011. Transcriptomic and proteomic analysis of the plant response to nematode infection. In: Jones J, Gheysen G, Fenoll C, eds. Genomics and molecular genetics of plant-nematode interactions. Dordrecht, Heidelberg, London \& New York: Springer, 157-173.

Favery B, Complainville A, Vinardell JM, Lecomte P, Vaubert D, Mergaert P, Kondorosi A, Kondorosi E, Crespi M, Abad P. 2002. The endosymbiosisinduced genes ENOD40 and CCS52a are involved in endoparasitic-nematode interactions in Medicago truncatula. Molecular Plant-Microbe Interactions 15: 1008-1013.

Favery B, Quentin M, Abad P. 2011. Compatible plant-root-knot nematode interaction and parallels with symbiosis. In: Perotto S, Baluška F, eds. Signaling and communication in plant symbiosis, signaling and communication in plants. Berlin \& Heidelberg, Germany: Springer-Verlag, 239-258.

Fischer HM. 1994. Genetic regulation of nitrogen fixation in rhizobia. Microbiological Reviews 58: 352-386. 
Fosu-Nyarko J, Jones MGK, Wang Z. 2009. Functional characterization of transcripts expressed in early-stage Meloidogyne javanica-induced giant cells isolated by laser microdissection. Molecular Plant Pathology 10: 237-248.

Fuller VL, Lilley CJ, Atkinson HJ, Urwin P. 2007. Differential gene expression in Arabidopsis following infection by plant-parasitic nematodes Meloidogyne incognita and Heterodera schachtii. Molecular Plant Pathology 8: 595-609.

Gagnot S, Tamby J-P, Martin-Magniette M-L, Bitton F, Taconnat L, Balzergue S, Aubourg S, Renou J-P, Lecharny A, Brunaud V. 2008. CATdb: a public access to Arabidopsis transcriptome data from the URGV-CATMA platform. Nucleic Acids Research 36: D986-D990.

Gamas P, de Billy F, Truchet G. 1998. Symbiosis-specific expression of two Medicago truncatula nodulin genes, $M t N 1$ and $M t N 13$, encoding products homologous to plant defense proteins. Molecular Plant-Microbe Interactions 11: 393-403.

Ge Y, Dudoit S, Speed T. 2003. Resampling-based multiple testing for microarray data analysis. Test 12: 1-77.

Gentleman R, Carey V, Bates D, Bolstad B, Dettling M, Dudoit S, Ellis B, Gautier L, Ge Y, Gentry J et al. 2004. Bioconductor: open software development for computational biology and bioinformatics. Genome Biology 5 : R80.

Gheysen G, Fenoll C. 2002. Gene expression in nematode feeding sites. Annual Review of Phytopathology 40: 191-219.

Gibson KE, Kobayashi H, Walker GC. 2008. Molecular determinants of a symbiotic chronic infection. Annual Review of Genetics 42: 413-441.

Goverse A, Bird D. 2011. The role of plant hormones in nematode feeding cell formation. In: Jones J, Gheysen G, Fenoll C, eds. Genomics and molecular genetics of plant-nematode interactions. Dordrecht, Heidelberg, London \& New York: Springer, 325-347.

Goyer A, Illarionova V, Roje S, Fischer M, Bacher A, Hanson AD. 2004. Folate biosynthesis in higher plants. cDNA cloning, heterologous expression, and characterization of dihydroneopterin aldolases. Plant Physiology 135: 103-111.

Graham MA, Silverstein KAT, Cannon SB, VandenBosch KA. 2004. Computational identification and characterization of novel genes from legumes. Plant Physiology 135: 1179-1197.

Grundler F, Hofmann J. 2011. Water and nutrient transport in nematode feeding sites. In: Jones J, Gheysen G, Fenoll C, eds. Genomics and molecular genetics of plant-nematode interactions. Dordrecht, Heidelberg, London \& New York: Springer, 423-439.

Grunewald W, van Noorden G, Van Isterdael G, Beeckman T, Gheysen G, Mathesius U. 2009. Manipulation of auxin transport in plant roots during Rhizobium symbiosis and nematode parasitism. The Plant Cell 21: 2553-2562.

Hammes UZ, Schachtman DP, Berg RH, Nielsen E, Koch W, McIntyre LM, Taylor CG. 2005. Nematode-induced changes of transporter gene expression in Arabidopsis roots. Molecular Plant-Microbe Interactions 18: 1247-1257.

Harrison MJ. 1999. Biotrophic interfaces and nutrient transport in plant/fungal symbioses. Journal of Experimental Botany 50: 1013-1022.

Ibrahim H, Hosseini P, Alkharouf N, Hussein E, Gamal El-Din AEK, Aly M, Matthews B. 2011. Analysis of gene expression in soybean (Glycine max) roots in response to the root-knot nematode Meloidogyne incognita using microarrays and KEGG pathways. BMC Genomics 12: 220.

Irizarry RA, Hobbs B, Collin F, Beazer-Barclay YD, Antonellis KJ, Scherf U, Speed TP. 2003. Exploration, normalization, and summaries of high density oligonucleotide array probe level data. Biostatistics 4: 249-264.

Jammes F, Lecomte P, de Almeida-Engler J, Bitton F, Martin-Magniette ML, Renou JP, Abad P, Favery B. 2005. Genome-wide expression profiling of the host response to root-knot nematode infection in Arabidopsis. The Plant Journal 44: 447-458.

Jarsch IK, Ott T. 2010. Perspectives on remorin proteins, membrane rafts, and their role during plant-microbe interactions. Molecular Plant-Microbe Interactions 24: 7-12.

Jones MGK. 1981. The development and function of plant cells modified by endoparasitic nematodes. In: Zuckerman BM, Rhode RA, eds. Plant parasitic nematodes. New York, NY, USA: Academic Press, 225-279.

Karimi M, Inze D, Depicker A. 2002. GATEWAY vectors for Agrobacteriummediated plant transformation. Trends in Plant Science 7: 193-195.

Kerk NM, Ceserani T, Tausta SL, Sussex IM, Nelson TM. 2003. Laser capture microdissection of cells from plant tissues. Plant Physiology 132: 27-35.
Koltai H, Dhandaydham M, Opperman C, Thomas J, Bird D. 2001. Overlapping plant signal transduction pathways induced by a parasitic nematode and a rhizobial endosymbiont. Molecular Plant-Microbe Interactions 14: 1168-1177.

Lafay B, Bullier E, Burdon JJ. 2006. Bradyrhizobia isolated from root nodules of Parasponia (Ulmaceae) do not constitute a separate coherent lineage. International Journal of Systematic and Evolutionary Microbiology 56: 1013-1018.

Lefebvre B, Timmers T, Mbengue M, Moreau S, Hervé C, Toth K, Bittencourt-Silvestre J, Klaus D, Deslandes L, Godiard L et al. 2010. A remorin protein interacts with symbiotic receptors and regulates bacterial infection. Proceedings of the National Academy of Sciences, USA 107: 23432348.

Limpens E, Ovchinnikova E, Journet E-P, Chabaud M, Cosson V, Ratet P, Duc G, Fedorova E, Liu W, Op den Camp R et al. 2011. IPD3 controls the formation of nitrogen-fixing symbiosomes in pea and Medicago spp. Molecular Plant-Microbe Interactions 24: 1333-1344.

Lin R-C, Park H-J, Wang H-Y. 2008. Role of Arabidopsis RAP2.4 in regulating light- and ethylene-mediated developmental processes and drought stress tolerance. Molecular Plant 1: 42-57.

Lipka V, Panstruga R. 2005. Dynamic cellular responses in plant-microbe interactions. Current Opinion in Plant Biology 8: 625-631.

Livak KJ, Schmittgen TD. 2001. Analysis of relative gene expression data using real-time quantitative PCR and the $2^{-\Delta \Delta \mathrm{C}_{\mathrm{T}}}$ method. Methods 25: 402-408.

Lohar DP, Bird DM. 2003. Lotus japonicus: a new model to study root-parasitic nematodes. Plant and Cell Physiology 44: 1176-1184.

Mathesius U, Schlaman HR, Spaink HP, Of Sautter C, Rolfe BG, Djordjevic MA. 1998. Auxin transport inhibition precedes root nodule formation in white clover roots and is regulated by flavonoids and derivatives of chitin oligosaccharides. The Plant Journal 14: 23-34.

Maunoury N, Redondo-Nieto M, Bourcy M, Van de Velde W, Alunni B, Laporte P, Durand P, Agier N, Marisa L, Vaubert D et al. 2010. Differentiation of symbiotic cells and endosymbionts in Medicago truncatula nodulation are coupled to two transcriptome-switches. PLoS ONE 5: e9519.

Mazarei M, Lennon KA, Puthoff DP, Rodermel SR, Baum TJ. 2003. Expression of an Arabidopsis phosphoglycerate mutase homologue is localized to apical meristems, regulated by hormones, and induced by sedentary plant-parasitic nematodes. Plant Molecular Biology 53: 513-530.

Mergaert P, Nikovics K, Kelemen Z, Maunoury N, Vaubert D, Kondorosi A, Kondorosi E. 2003. A novel family in Medicago truncatula consisting of more than 300 nodule-specific genes coding for small, secreted polypeptides with conserved cysteine motifs. Plant Physiology 132: 161-173.

Moreau S, Verdenaud M, Ott T, Letort S, de Billy F, Niebel A, Gouzy J, de Carvalho-Niebel F, Gamas P. 2011. Transcription reprogramming during root nodule development in Medicago truncatula. PLoS ONE 6: e16463.

Newton AC, Fitt BDL, Atkins SD, Walters DR, Daniell TJ. 2010. Pathogenesis, parasitism and mutualism in the trophic space of microbe-plant interactions. Trends in Microbiology 18: 365-373.

van Noorden GE, Kerim T, Goffard N, Wiblin R, Pellerone FI, Rolfe BG, Mathesius U. 2007. Overlap of proteome changes in Medicago truncatula in response to auxin and Sinorhizobium meliloti. Plant Physiology 144: 11151131.

Oldroyd GED, Engstrom EM, Long SR. 2001. Ethylene inhibits the Nod factor signal transduction pathway of Medicago truncatula. The Plant Cell 13: 18351849.

Osakabe Y, Miyata S, Urao T, Seki M, Shinozaki K, Yamaguchi-Shinozaki K. 2002. Overexpression of Arabidopsis response regulators, ARR4/ATRR1/IBC7 and ARR8/ATRR3, alters cytokinin responses differentially in the shoot and in callus formation. Biochemical and Biophysical Research Communications 293: 806-815.

Parniske M. 2000. Intracellular accommodation of microbes by plants: a common developmental program for symbiosis and disease? Current Opinion in Plant Biology 3: 320-328.

Plet J, Wasson A, Ariel F, Le Signor C, Baker D, Mathesius U, Crespi M, Frugier F. 2011. MtCRE1-dependent cytokinin signaling integrates bacterial and plant cues to coordinate symbiotic nodule organogenesis in Medicago truncatula. The Plant Journal 65: 622-633. 
Puthoff DP, Ehrenfried ML, Vinyard BT, Tucker ML. 2007. GeneChip profiling of transcriptional responses to soybean cyst nematode, Heterodera glycines, colonization of soybean roots. Journal of Experimental Botany 58 : 3407-3418.

Quandt HJ, Pühler A, Broer I. 1993. Transgenic root-nodules of Vicia hirsutaa fast and efficient system for the study of gene-expression in indeterminatetype nodules. Molecular Plant-Microbe Interactions 6: 699-706.

Saha D, Prasad AM, Srinivasan R. 2007. Pentatricopeptide repeat proteins and their emerging roles in plants. Plant Physiology and Biochemistry 45: 521-534.

Thimm O, Blasing O, Gibon Y, Nagel A, Meyer S, Kruger P, Selbig J, Muller LA, Rhee SY, Stitt M. 2004. MAPMAN: a user-driven tool to display genomics data sets onto diagrams of metabolic pathways and other biological processes. The Plant Journal 37: 914-939.

Trudgill DL, Blok VC. 2001. Apomictic, polyphagous root-knot nematodes: exceptionally successful and damaging biotrophic root pathogens. Annual Review of Phytopathology 39: 53-77.

Van de Velde W, Guerra JCP, Keyser AD, De Rycke R, Rombauts S, Maunoury N, Mergaert P, Kondorosi E, Holsters M, Goormachtig S. 2006. Aging in legume symbiosis. A molecular view on nodule senescence in Medicago truncatula. Plant Physiology 141: 711-720.

Van de Velde W, Zehirov G, Szatmari A, Debreczeny M, Ishihara H, Kevei Z, Farkas A, Mikulass K, Nagy A, Tiricz H et al. 2010. Plant peptides govern terminal differentiation of bacteria in symbiosis. Science 327: 1122-1126.

Vandesompele J, De Preter K, Pattyn F, Poppe B, Van Roy N, De Paepe A, Speleman F. 2002. Accurate normalization of real-time quantitative RT-PCR data by geometric averaging of multiple internal control genes. Genome Biology 3: RESEARCH0034.

Weerasinghe RR, Bird DM, Allen NS. 2005. Root-knot nematodes and bacterial Nod factors elicit common signal transduction events in Lotus japonicus. Proceedings of the National Academy of Sciences, USA 102: 3147-3152.

Weinstein PP, Jaffe JJ. 1987. Cobalamin and folate metabolism in helminths. Blood Reviews 1: 245-253.

\section{Supporting Information}

Additional supporting information may be found in the online version of this article.

Fig. S1 Laser microdissection of infected root tissues.

Fig. S2 MapMan representation of deregulated genes belonging to the 'Mitochondrial electron transport' functional category, using the mapping 'Mt_AFFY_Mt3.0_0510.m02'.

Fig. S3 Number of probe sets deregulated in giant cells and surrounding cells classified into subcategories of the BIN class 'Protein' from the mapping 'Mt_AFFY_Mt3.0_0510.m02'.
Table S1 Percentage of genes detected as expressed in Affymetrix gene chips

Table S2 Pearson correlation between biological replicates

Table S3 List of primers used for microarray validation by realtime PCR and promoter:GUS constructs

Table S4 List of statistically differentially expressed probe sets in at least one of our comparisons after Bonferroni correction $(P<0.05)$

Table S5 List of nodule marker genes

Table S6 List of genes, possessing an orthologous gene in Arabidopsis, statistically differentially expressed in giant cells (GC) and/or surrounding cells (SC) vs control cells from Medicago galls at 7 -d post-infection relative to GC at $3 \mathrm{dpi}$ from Arabidopsis (Barcala et al., 2010)

Table S7 Comparison between nodule zone II cells and wholenodule transcriptomic data

Table S8 Nodule zone II cell-only deregulated processes

Table S9 List of deregulated probe sets coding for nodule-specific cysteine rich (NCR) or nodulins in nodule zone II cells; nodules at 10,14 and $28 \mathrm{~d}$ post-infection

Table S10 Legume-specific genes deregulated in our analysis

Table S11 Differentially expressed transcription factor genes in our microarray experiments

Table S12 List of probe sets related to hormone metabolism and signalling deregulated in nodule zone II cells, giant cells and/or surrounding cells

Please note: Wiley-Blackwell are not responsible for the content or functionality of any supporting information supplied by the authors. Any queries (other than missing material) should be directed to the New Phytologist Central Office. 